\title{
Strategies for Improving Inhalation Technique in Children: A Narrative Review
}

This article was published in the following Dove Press journal:

Patient Preference and Adherence

\author{
Anna Volerman' \\ Kristin Kan ${ }^{2,3}$ \\ Delesha Carpenter ${ }^{4}$ \\ Valerie G Press' \\ 'University of Chicago, Departments of \\ Medicine and Pediatrics, Chicago, IL, \\ USA; ${ }^{2}$ Division of Advanced General \\ Pediatrics and Primary Care, Ann \& \\ Robert H. Lurie Children's Hospital of \\ Chicago, Chicago, IL, USA; \\ ${ }^{3}$ Northwestern University Feinberg \\ School of Medicine, Advanced General \\ Pediatrics Division, Department of \\ Pediatrics, Chicago, IL, USA; ${ }^{4}$ University \\ of North Carolina at Chapel Hill, Division \\ of Pharmaceutical Outcomes and Policy, \\ Chapel Hill, NC, USA
}

\begin{abstract}
Inhaled medicines are commonly utilized by children for various respiratory conditions and must be used effectively for the medication to reach the airways. Poor inhaler technique contributes to poorly controlled asthma with significant associated morbidity. Given the significant consequences of improper inhaler use in children, the goal of this review is to comprehensively describe existing and potential solutions to improve inhaler technique. Because children move through various settings, including clinical practices, schools, pharmacies, and homes, in their daily routine, there is great opportunity to teach and reinforce proper inhaler technique across settings. Within each setting, in-person and technology-based interventions have shown promise to improve technique. These solutions need to be more broadly adopted to deliver tailored education with support for provider training, team-based care, communication structures, and reimbursement. Such solutions hold the potential to improve inhaler use among children, with potential for decreasing morbidity and costs.
\end{abstract}

Keywords: asthma, devices, inhalers, pediatric

\section{Introduction}

Inhaled medicines are commonly utilized by children for various respiratory conditions, such as asthma, cystic fibrosis, and chronic lung disease/bronchopulmonary dysplasia. Delivered via nebulizer machines and inhaler devices ("inhalers"), these medicines are fundamental to effective disease management and offer many clinical advantages. One key benefit is that inhaled medicines act locally in the lungs, thus minimizing their systemic effects on the rest of the body.

Inhalers are shown to be at least as effective as nebulizers and have the added benefits of portability and access. ${ }^{1}$ However, for inhaled medications to be effective, their fine particles must be delivered directly into the airways. It is critical that each person with a respiratory condition is able to use their inhaler correctly to support disease management. Improper inhaler technique (also termed inhaler misuse) is a key reason that inhaled medicines are not effective, as the medicine does not reach the airways. ${ }^{2-4}$ Inhaler misuse contributes to poorly controlled asthma with resultant exacerbations, steroid use, acute care utilization (urgent care and emergency department visits), as well as hospitalization. ${ }^{3,5-7}$ In addition to negative clinical outcomes, improper inhaler use leads children to miss school and parents to miss work. The financial cost of inhaler misuse is estimated at \$7-15 billion annually. ${ }^{8}$ Indirect effects of inhaler misuse include patient or caregiver loss of confidence in their medications and
Correspondence: Valerie G Press University of Chicago, 584I S Maryland, MC 2007, Chicago, IL, 60637, USA

Tel + I 773-702-5I70

Fax + I 773-834-2288

Email vpress@bsd.uchicago.edu
Patient Preference and Adherence 2021:15 665-675 in $\square$

http://doi.org/10.2147/PPA.S267053 
treatment plan, worse medication adherence, as well as escalation of therapy with associated potential side effects. $^{7}$

Research indicates that poor inhaler technique is common among children. ${ }^{9}$ Specifically, observational studies have found that only $8-22 \%$ of children with asthma use their inhalers correctly. ${ }^{9}$ High rates of inhaler misuse are present across ages, race/ethnicity, geographic variation, places in care, and conditions. ${ }^{9,10}$ As a result, guidelines recommend that healthcare professionals educate about proper inhaler use at each patient encounter. ${ }^{1,12}$ Despite these guidelines, a sizeable $(25 \%)$ proportion of patients who use inhalers do not receive inhaler instruction. ${ }^{13}$ Among children, one study found that only $10 \%$ had their inhaler technique assessed by their provider during an office visit. ${ }^{14}$ This limited education represents missed opportunities to improve asthma outcomes among children.

\section{Effective Inhaler Technique}

Proper inhaler technique involves knowing each step for effective use and implementing maintenance and cleaning procedures to ensure that the devices continue to work effectively. Inhaler technique varies by device (eg, metered dose inhalers (MDIs), diskus, turbohalers), with each inhaler type requiring different steps for correct use. ${ }^{13}$ There are no set standards for proper or effective technique; however, a variety of checklists or review criteria have been published. ${ }^{15}$ Within this literature, evidence is emerging about the importance of "critical" errors, defined as errors that have the greatest impact on effective medication delivery on clinical outcomes. ${ }^{16}$ Further, proper technique varies according to patients' age and abilities. For instance, younger patients require both a mask and spacers with MDIs, while older patients can effectively use just a spacer with MDIs. ${ }^{17}$ No guidelines establish what factors should drive this change or at what age this change should occur, though it is typically posited to be around 5 years of age. $^{17}$

In addition to age as a factor for proper technique, inhaler devices differ in terms of how easy or difficult it is to use them. ${ }^{18}$ Devices that are generally considered easier to use include diskus, turbohaler, and ellipta, because the steps required for effective use are more obvious and/or it is more difficult to conduct critical errors. $^{9,14,18,19}$ Metered dose inhalers, despite being the first device developed to deliver inhaled medications to the lungs, are considered more challenging to use than most other devices. ${ }^{19,20}$ This is in large part due to the difficulty, if not near impossibility, of effectively "coordinating" the breath in after device activation such that the medication reaches the lungs rather than the gastrointestinal tract. Common teachings include instructing patients on how to coordinate this breath in; however, the speed at which the medication leaves the device after actuation is simply too fast for a person to be able to effectively inhale most of the medication without the use of a spacer. Spacers are separate devices that require a prescription and money to purchase. Also, adolescents often report that using a spacer is inconvenient, creating an additional barrier to proper inhaler technique in pediatric patients. ${ }^{21}$ Further complicating matters is the fact that many patients require more than one inhaler device to manage their asthma. Some data suggest that multiple devices can lead to worse technique, ${ }^{2,23}$ though at least one study did not find these results. ${ }^{24}$ Finally, with every inhaler a patient is prescribed, risk of misuse is increased. ${ }^{25}$

According to the national asthma guidelines, factors that promote good technique include clinician assessment of patient technique and provision of technique education at all healthcare encounters. ${ }^{11}$ Multiple options exist for inhaler technique education and the type of education that clinicians use to teach patients about inhaler technique matters. For example, in one study of hospitalized adults with obstructive lung disease, inhaler education that utilized an active learning approach with assessment and teach-back, termed teach-to-goal, was found to be more effective at reducing acute care utilization (ED visits and/ or re-hospitalizations) within 30 days after hospital discharge compared to simply providing brief verbal instructions. $^{26}$ Also, education is critical and cannot be substituted by assessing a child's or parent's confidence in technique, as studies show that confidence and proper technique are not aligned. ${ }^{27}$ However, assessing patients' confidence in their technique is important because patients' adherence to their regimen is predicted by confidence. ${ }^{28}$ Further, when patients have low confidence in their technique, they also report worse adherence. ${ }^{29}$ Providing repeated education on correct inhaler technique has been found to improve adherence. ${ }^{30}$

Given the significant consequences of improper inhaler use in children, the goal of this review is to comprehensively describe existing and potential solutions to improve inhaler technique. This paper first describes solutions to improve technique and explores existing solutions and future directions by the healthcare delivery setting. For this narrative 
review, relevant English language articles from any year were identified from PubMed, Google Scholar, and Embase databases using keyword searches for "inhaler technique", "inhaler competence", "inhaler misuse", "diskus technique", "metered dose inhaler technique", and "inhaler education", "children", and "pediatric". The references of relevant articles were reviewed for additional papers.

\section{Results}

\section{Measuring Inhaler Technique}

Instruments, such as questionnaires or checklists, are utilized to measure inhaler technique in research studies in order to quantify the adequacy of inhaler technique. However, no standard tool is used for asthma education in routine clinical delivery. Part of the challenge may be attributed to the numerous inhaler technique instruments available. In a systematic review of 24 available instruments to measure pressurized MDI technique among children with asthma, four instruments were designated as higher quality based on appropriateness of measurement and evidence of validation. ${ }^{31}$ The conclusion, however, is that no single instrument has been fully evaluated to ensure appropriate validity and reliability for adoption into clinical practice. Most experimental or observational studies for MDI technique used an 8-step reference to measure correct use. ${ }^{9}$ Other researchers have suggested that not all steps in inhaler technique should be weighted equally and it may be more meaningful for practicing clinicians to distinguish whether the step is a critical error (eg, not taking the cap off the inhaler) versus a non-essential error (eg, not holding the inhaler upright). ${ }^{9,32}$

\section{Solutions to Improve Inhaler Technique}

Because children move through various settings, including clinical practices, schools, pharmacies, and homes (Figure 1), as part of their daily routine, there is great opportunity to teach and reinforce proper inhaler technique across these settings. Within each setting, several interventions can be implemented to support children's asthma management and inhaler technique. Also, some of these solutions can be implemented across settings. We outline these solutions by setting below and note when interventions overlap across settings (Table 1).

\section{Clinical: Outpatient and Inpatient}

The outpatient setting, either primary care or specialty clinics (pulmonary or allergy), remains the most common location to provide comprehensive, high-quality, longitudinal care for

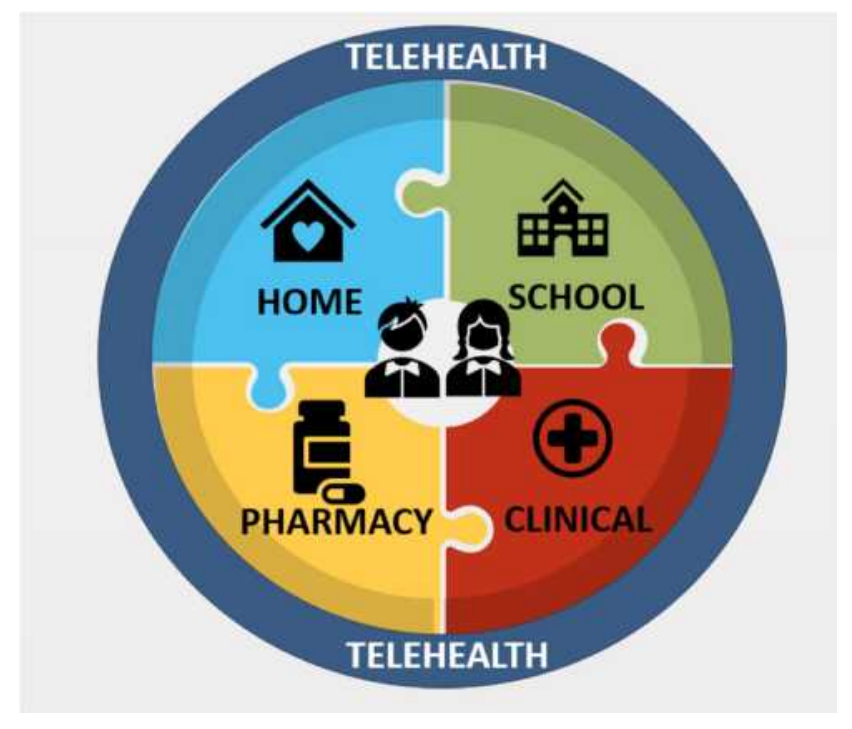

Figure I Settings in which inhaler technique solutions can be implemented.

children with asthma. ${ }^{33}$ National Heart, Lung, and Blood Institute guidelines that recommend healthcare professionals check inhaler technique at every opportunity seems most apt for the outpatient clinical setting. ${ }^{11}$ However, evaluations of outpatient asthma visits found that most health providers, particularly physicians, do not take the time to review and assess the use of inhalers with their pediatric patients with asthma. ${ }^{14}$ Additionally, patients have a low return rate for preventive asthma visits, which necessitates that other clinical settings, such as the emergency department or urgent care, must be considered as settings for education and reinforcement of proper inhaler technique. ${ }^{34}$ Further, a hospitalization represents a critical event and important opportunity for education. Thus, we review solutions for assessment and education of inhaler technique that are used in various clinical settings, including office-based visits, emergency departments, and inpatient settings.

Educational interventions focused on inhalation technique generally improve children's technique significantly regardless of whom (ie, nurse, physician, asthma educator) provides the education. ${ }^{9}$ While some educational interventions were delivered during scheduled clinic visits, others were done at follow-up clinic visits 1 to 12 months after the initial assessment. Most importantly, frequent opportunities to observe and correct technique are needed for children and caregivers to maintain proper technique. Educational interventions can use face-to-face support, multimedia delivery (eg, apps, games), and technologyenhanced feedback devices. Each educational modality 
Table I Solutions, Educators, Themes, and Future Directions to Improve Inhaler Technique in Children

\begin{tabular}{|c|c|c|c|}
\hline Solutions & Educators & Themes & Future Directions \\
\hline $\begin{array}{l}\text { Education types: } \\
\text { - Written material - eg } \\
\text { paper, pamphlet } \\
\text { - Videos - } \\
\text { - In-person - with } \\
\text { demonstration and } \\
\text { teach-back } \\
\text { - Technology-enabled } \\
\text { supports - device- } \\
\text { based and telehealth } \\
\text { education }\end{array}$ & $\begin{array}{l}\text { - } \text { Doctors } \\
\text { Practice } \\
\text { providers } \\
\text { - Pharmacists } \\
\text { - Nurses } \\
\text { - Respiratory } \\
\text { therapists } \\
\text { - Medical } \\
\text { assistants } \\
\text { Community } \\
\text { health } \\
\text { workers }\end{array}$ & $\begin{array}{l}\text { - Most education can be implemented in } \\
\text { multiple settings by various educators } \\
\text { - Many inhaler technique education mod- } \\
\text { used in alone or in combination } \\
\text { - Education should be tailored to indivi- } \\
\text { dual's knowledge and skill } \\
\text { - Active learning methods are most effec- } \\
\text { tive and can be supplemented by written } \\
\text { and videos to reinforce education } \\
\text { - Team-based approach is crucial for deli- } \\
\text { vering education }\end{array}$ & $\begin{array}{l}\text { - Provide reimbursement for inhaler technique educa- } \\
\text { tion for all patient ages and various health } \\
\text { - Exofessionals } \\
\text { - Ensure consistent coverage for telehealth services } \\
\text { - Advance communication systems between health } \\
\text { professionals to enable easy bi-directional informa- } \\
\text { tion flow } \\
\text { - Change appearance and structure of inhaler devices } \\
\text { to support effective use, including consistent colors, } \\
\text { built-in spacers, and real-time feedback } \\
\text { - Adopt training about proper inhaler technique for } \\
\text { health professionals broadly } \\
\text { Support research on improve inhaler use, such as } \\
\text { assessment tools, practical interventions, and } \\
\text { implementation }\end{array}$ \\
\hline
\end{tabular}

Notes: Education can be provided synchronously or asynchronously. Checklists can be helpful to assess technique.

improves technique in adults and children in comparison to usual care. ${ }^{32}$

In-person education, defined as live instruction typically with a health provider, is the most common approach for educational interventions on inhaler technique in clinical care. Studies often describe hands-on demonstration with patients and verbal instruction to reinforce technique with patients. ${ }^{35}$ Educational approaches have also included a "teachback" process from patients, such as Teach-toGoal (TTG). This standardized in-person educational intervention is one evidence-based approach to improve inhaler technique. In TTG, learner's skills and knowledge of inhaler technique are assessed and tailored education is provided. The learner then re-demonstrates technique as "teachback". The cycle is repeated until learners demonstrate skills mastery. ${ }^{36}$ TTG has been effective among $8^{-}$ 14-year-old children, with one study showing improvement in the number of correct steps performed, an increase in the proportion of children with mastery (all steps correct), and a decrease in the proportion of children with inhaler misuse. $^{37}$

\section{Multimedia Interventions}

Videos are an additional education tool that can be used to provide step-by-step physical demonstrations of how to use inhalers. Videos have the advantage of demonstrating proper inhaler technique while ensuring high fidelity (ie, the process is taught the same way to different patients); however, they do not allow for a teach-back process. Videos have been created for different inhalation devices, age groups, genders, and even languages, thus creating a tailored experience for the child. Various organizations have developed videos that are readily accessible online. ${ }^{38,39}$ Benefits of videos include the ability to integrate them in clinical workflows, the ease of access in clinical environments and at home, the opportunity to deliver training to additional caregivers or family members, as well as cost-effectiveness and sustainability. ${ }^{40}$

Technology-enabled supports have emerged as additional tools in asthma education in the clinical setting. Various types of technology-enabled devices or programs are available for teaching inhaler technique, including device-based interventions and telehealth for enhanced education. Electronic devices often externally attach to the inhaler and detect when the patient activates (or uses) the inhaler. For example, Ammari et al conducted a trial where children used a device designed to support their coordination with slow, deep breaths to improve the manual delivery of inhaled medication via MDI.$^{41}$ In the study, the device proved equally effective in helping children master MDI technique when compared with traditional verbal counseling about technique. In addition to qualitative feedback typically given to patients about inhaler technique, a mobile spirometer, a machine for pulmonary function testing, has been studied to also give patients quantitative feedback about technique. ${ }^{42}$ These are two 
examples of the various devices available to support inhaler technique. Notably, a recent review found that many devices do not include all the evidence-based steps for inhaler technique and have limited real-time feedback. ${ }^{7}$

Telehealth educational sessions have been increasingly adopted to further connect with patients with clinicians without requiring in-person visits. Since the COVID-19 pandemic, telehealth approaches have accelerated within clinical practice ${ }^{43,44}$ Despite the limited evidence on using televideo visits for children with asthma, they might become more prevalent due to changes in practice norms and capacity. Further, they enable chronic disease management without requiring families to attend office-based visits, thus overcoming barriers with transportation or missed work/school. In a prospective 12 month randomized trial using asynchronous, in-home asthma monitoring, pediatric patients in the virtual group demonstrated improved MDI technique compared with the office-based only group at 52 weeks. There was no difference in drypowder inhaler technique in the trial between the two groups. ${ }^{24}$ Notably, to overcome technology and equipment barriers, families were provided a home computer, camera, and internet access in the trial. The limited evidence suggests that telemedicine was non-inferior to office-based visits for asthma. ${ }^{45}$

\section{Community Pharmacies}

Across the United States, there are over 68,000 pharmacies, many of which have convenient hours and offer free medication counseling services without the need for an appointment. ${ }^{46}$ These factors mean that pharmacies have an important role in play in educating children about their inhaled medications. In fact, pharmacists are uniquely positioned to assess inhaler technique and deliver education each time an inhaler prescription is filled. Studies suggest that both children and their caregivers are receptive to receiving medication education from pharmacists. ${ }^{47}$ Although pharmacies offer distinct advantages for inhaler technique education, many children do not accompany caregivers when they pick up their prescriptions. ${ }^{7,48}$ Despite this barrier to pharmacist assessment of technique, several viable inhaler technique education solutions are currently offered in pharmacies. Indeed, a recent review found that inhaler technique education was a common component of pharmacistdelivered asthma interventions. ${ }^{49}$ We describe various pharmacy-based solutions below.

In-person assessment and education is the most common intervention implemented in community pharmacies. Face- to-face demonstration and assessment have been described previously in the clinical settings section, and the same teaching principles apply in the community pharmacy setting. Face-to-face instruction has shown benefits at both the patient and pharmacy level. ${ }^{50-52}$ For example, one study found that when pharmacists asked patients to demonstrate inhaler technique, patients were more likely to return to the pharmacy as compared to when pharmacists did not ask patients to demonstrate technique. ${ }^{50}$ Additionally, pharmacy-based face-to-face demonstrations have led to greater improvements in patient inhaler technique when compared to written materials or videos. ${ }^{52}$

Face-to-face interventions have ranged from simple onetime assessments that led to short-term reductions in inhaler technique errors to more comprehensive interventions that are associated with long-term technique improvements. ${ }^{53,54}$ Specifically, one multifaceted intervention involved pharmacists: (1) asking patients with chronic obstruction pulmonary disease to demonstrate inhaler technique using a placebo device; (2) providing verbal one-on-one instruction with a physical demonstration of correct technique; (3) asking the patient to teach-back correct technique after the pharmacist demonstration; and (4) attaching a reminder label with the steps for correct technique to the patient's device. ${ }^{54}$ Pharmacists repeated this intervention at 1, 3, and 6-month follow-up. The authors found that patients had sustained statistically significant improvements in technique at 12month follow-up, illustrating the effectiveness of repeated inhaler technique assessments by pharmacists. Further research is needed to determine whether this strategy would be an effective method for providing education to children and their parents.

Written materials have also been used to teach inhaler technique in pharmacy settings. Pharmacists use written materials independently and/or to reinforce verbal instruction about proper technique. Common written materials include handouts and pamphlets with detailed instructions. Another simple, innovative intervention involves having the pharmacist place a label on the inhaler with step-bystep instructions for correct use. ${ }^{55}$ This intervention provides a visual cue to think about proper technique each time the individual uses their inhaler.

\section{Multimedia and Telehealth Interventions}

Pharmacists have also used multimedia and telehealth interventions to deliver inhaler technique education to patients. Multimedia interventions typically include videos, ${ }^{52}$ while telehealth interventions include phone 
calls or video visits. One small study found that three telepharmacy visits from a pharmacist led to significantly improved MDI technique among 36 adolescents when compared with a control group. ${ }^{56}$ The pharmacist used a checklist to assess technique, provided verbal demonstrations and instruction on how to correct errors via a video visit. Additionally, a study in which rural patients had three to four video telehealth visits with a pharmacist demonstrated sustained improvements in inhaler technique at 2-month follow-up. ${ }^{57}$ Given that multimedia and telehealth interventions show promise, future studies should evaluate the effect of these pharmacy-based interventions on children's inhaler technique.

\section{Schools}

Children spend more than half of their waking hours in school. As such, there are several benefits to offering inhaler technique education in schools, including access to children who attend schools; on-site school nurses who can assess and educate about technique; opportunity to conduct periodic follow-up assessments and education throughout the school year; and no need for parents to miss work days and children to miss school.

\section{Face-to-Face Assessment and Education}

Research has shown that school-based asthma education improves children's knowledge of asthma, self-efficacy, and self-management. ${ }^{58}$ Unfortunately, a review of schoolbased asthma education programs found that the methods used to teach technique are poorly described, and only two studies used a validated measure to evaluate whether participation in the program improved children's inhaler technique. $^{59}$ Of the articles that described inhaler technique education in greater detail, inhaler technique was typically addressed only once in the curriculum, with 10 minutes or less dedicated to teaching technique. Thus, there is great opportunity to augment inhaler technique instruction in these comprehensive school-based programs that address other important asthma self-management behaviors, such as environmental control, symptom monitoring, and medication adherence.

\section{Multimedia, Telehealth, and Technology-Enabled Interventions}

School nurses have used tailored inhaler technique videos to improve children's inhaler technique. ${ }^{60}$ Additionally, emerging evidence suggests that school-based asthma telehealth programs can reduce emergency department visits for children with asthma. Perry and colleagues (2019) have provided a recent, comprehensive review of schoolbased asthma telehealth programs and their potential benefits. ${ }^{61}$ However, the extent to which inhaler technique is addressed during school-based telehealth visits is unknown. Although inhaler technique has not been a focus of existing school-based telehealth programs, the potential to deliver inhaler technique education during telehealth visits is great. Additionally, school nurses can reinforce proper technique in between telehealth visits and share children's inhaler technique assessments with their providers during telehealth visits, expanding the opportunities to provide team-based care. One pilot study demonstrated that children who received school-based telehealth visits with an asthma specialist and adherence psychologist combined with inhaler use monitoring via the Propellor device demonstrated improvements in asthma symptoms and medication adherence. ${ }^{62}$ Taken together, these studies suggest that assessing and educating about inhaler technique during school-based telehealth visits is a worthwhile area for future study.

\section{Home Environment}

Supporting families with children with asthma directly in their home environment is also an evidence-based, effective approach. ${ }^{63}$ In the home, education can occur synchronously or asynchronously, thus expanding access to inhaler technique education for children, their parents/ guardians, and additional caregivers in the home. Synchronous education can occur in person or via telehealth. Also, asynchronous education can utilize videos or websites with reputable information, for example from health systems, community coalitions, or pharmaceutical companies, can deliver education at a convenient time and can allow for repetition of education.

Home-based programs have been studied as multicomponent interventions that evaluate home environmental triggers, assess knowledge and challenges with asthma self-management, and support asthma control. ${ }^{64,65}$ Less explicitly mentioned in these studies is whether asthma basics or self-management education includes review of inhaler technique in these home-based programs.

In a study of in-home assessment of urban minority youth with asthma, evaluations found that participants had a lack of asthma medications and devices as well as improper asthma management. ${ }^{66}$ These findings point to the advantage of having in-home evaluations to offer a more accurate picture of what patients and families 
experience. Intervening on inhaler technique in this setting then seems appropriate. For example, a feasibility study using community health workers (CHW) for children with comorbid obesity and asthma found that inhaler technique can be improved even in a combined intervention focused on two conditions among high-risk children. ${ }^{67}$

\section{Discussion}

\section{Themes}

Several patterns emerge as we examine existing solutions across settings (Table 1). Strategies to improve inhaler technique among children range from in-person to technology-based, both synchronously and asynchronously. These strategies enable children and their caregivers to be reached where they are at, both in terms of location and skill. Written materials are available but have been proven to have limited effectiveness when compared to more intense teaching methods. With both in-person and technology-based approaches, opportunities exist to tailor education to the individual's knowledge and skill by making assessments and adjustments in real-time. Further, a tailored approach allows the education to be modified for different learning styles. These active learning methods can be supplemented by written materials and videos for reinforcement, which is critical to maintain effective inhaler technique.

With each strategy, education can be delivered by various individuals - physicians, advanced practice providers, pharmacists, nurses, respiratory therapists, medical assistants, community health workers, and others. Primary care doctors can teach effective technique in their clinics as well as refer to subspecialists for teaching and reinforcement. Advanced practice providers, pharmacists, nurses, and respiratory therapists can teach and reinforce proper technique in their encounters and interactions with the patient, either with the physician or separately. Expanding the scope of work of medical assistants and community health workers provides enhanced opportunities for education and reinforcement across settings, particularly by diverse team members with varying time availability and day structures. This team-based approach is often applied in cystic fibrosis models of care and lessons learned can be applied to other respiratory diseases. Further, this diffusion of responsibility also ensures that the burden is not on one person to deliver education but rather on all individuals. It also enables more frequent education for children, which proves crucial as children develop and their knowledge and skills change.

Notably, with a team-based approach, it is critical to ensure that everyone is aware of their role in teaching inhaler technique, as there is a risk that one clinician believes that another is doing the teaching. In addition, there must be a high level of skill among clinicians who are teaching proper technique and consistency in the technique taught across clinicians and clinical settings, as inconsistencies have the potential to lead to confusion and distrust among children and caregivers.

\section{Future Directions}

Building upon existing work, we propose solutions that could enhance inhaler technique education (Table 1). At the policy level, reimbursement is fundamental to ensure that healthcare professionals are better able to implement inhaler technique assessment and education for children with asthma. Currently, reimbursement varies widely by patient age, insurance, state, and clinical setting. ${ }^{68}$ In the United States, Medicare, a public insurance option for individuals over 65 years, reimburses clinicians for delivering inhaler technique education. This model could be replicated with children in clinical settings, community pharmacies, and homes to encourage more frequent inhaler technique education. Further, reimbursement needs to occur for various health professionals, not just physicians or advanced practice providers. For example, pharmacists, medical assistants, and school nurses are commonly not reimbursed for providing inhaler technique education, and, pharmacists, for example, may prioritize reimbursable services to ensure the financial viability of the pharmacy. Alternatively, there is preliminary evidence that trained pharmacy technicians and community health workers can identify and correct inhaler technique errors. ${ }^{69}$ Thus, they may represent an economically feasible method for providing inhaler technique education. Another potential solution is to expand the scope of practice of certain team members, for example allowing pharmacists to prescribe spacers and make adjustments to the child's inhaled medication type if the child repeatedly fails to demonstrate correct technique. Because pharmacists can assess technique on a monthly basis when the child's inhaler prescriptions are filled, they are well positioned to conduct regular technique assessments. To make the expansion of their scope of work feasible and sustainable, it is critical to match reimbursement to work. 
Also, in terms of policy, the shift from traditional clinic-based care to home and telehealth settings indicates that the landscape of care delivery for asthma is likely shifting. Telehealth is changing the paradigm about how we deliver care. How rapid or responsive systems are to this change depends partly on aligning reimbursement with health care services in these non-traditional settings. For example, with the COVID-19 pandemic, Medicare expanded its list of covered services via telehealth and modified the process to add covered telehealth care services in a more expedited way. ${ }^{70,71}$ Nevertheless, more US children are covered under Medicaid than private insurance, and the policies for covered telehealth services and remote monitoring are varied. ${ }^{72}$ Medicaid policies at the national level should be aligned broadly around coverage for telehealth services, which will directly affect coverage for asthma care telehealth services. Further, reimbursement for inhaler education, specifically, by Medicaid and private insurance should be advised, similar to the Medicare code, ${ }^{73}$ to encourage health professionals to educate about inhaler technique. Reimbursement could encourage provider adherence to national guidelines that recommend assessing and educating about technique at every visit.

As a team-based model that spans in-person and telehealth is increasingly adopted for asthma care, it is critical to advance communication systems. Health professionals currently work in silos and those individuals in different locations have limited, if any, communication. When team members span many different settings, effective communication infrastructure is essential. Implementing a shared medical record enables easy bi-directional information flow without barriers such as waiting on the phone or faxing papers. Such systems would allow a pharmacist, for example, to share suggested medication changes with a medical professional when a child repeatedly demonstrates suboptimal technique and allows the clinician to comment on the appropriateness of the changes. Additionally, school nurses could communicate the need for medication and device refills or the increase of medication use that may require adjustment in the treatment plan. These communication systems are foundational to enhance the delivery of child-centered teambased asthma care.

At the systems level, changes to the appearance and structure of inhaler devices can support effective inhaler use. Pharmaceutical companies can start by simplifying the colors of devices, such as making all quick-relief inhalers one color and controller inhalers another color.
While it seems simple, such a change would reduce confusion that impacts inhaler use. Future efforts should focus on developing inhalers with built-in spacers to minimize barriers to proper inhaler use, including prescriptions and costs. In addition, devices that provide real-time feedback about technique hold potential to be more influential than those that deliver feedback at a later time. Pharmaceutical companies should engage children and parents in a usercentered design process to ensure their representation and experience are accounted for as inhalers are developed or redesigned. Finally, broad adoption of training for health professionals - including clinicians - about proper inhaler technique is necessary, as their limited knowledge, poor skills, and low confidence may preclude inhaler education for children and families. ${ }^{74}$ This need for education is particularly true as novel inhalers are developed and approved for clinical use.

Along with the adoption of solutions in the clinical, community, and policy realms, more research is also needed to broaden effective inhaler use among children with asthma. Racial and geographic disparities are well described among children with respiratory conditions; however, few studies have focused on disparities related to inhaler use. Research is needed to understand the prevalence and impact of inhaler misuse across children of different races/ethnicities as well as living in different geographic regions. For these studies to be effective and applicable to real-world practice, the tools for the assessment of inhaler technique should be standardized. Also, work must be done to identify practical, high-fidelity interventions to improve and maintain effective inhaler technique, including how best to adopt them in busy clinical settings and among competing demands. Research about asthma self-management and inhaler technique education suggests its benefit for children; however, issues exist with rigor and design of interventions across all settings. For example, studies do not detail the specifics of selfmanagement education, thus making it hard to understand the amount and type of inhaler education provided. Specific efforts must focus on detailing the inhaler education delivered to compare studies and ascertain educational components that should be more broadly adopted.

\section{Conclusion}

Poor inhaler technique is common among children and the effects of poor technique are broad. In-person and technology-based interventions have shown promise to improve technique. These solutions need to be more broadly 
adopted with support for provider training, team-based care, communication structures, and reimbursement. Such solutions hold the potential to improve inhaler use among children, with potential for decreasing morbidity and costs.

\section{Acknowledgments}

Thank you to Mary Akel for editorial assistance.

\section{Disclosure}

Dr. Volerman's effort was supported by grant number K23HL143128 from the National Heart, Lung, and Blood Institute. She also received funding from the Health Resources and Services Administration (Award Numbers HHSH250201300025I and 5T0BHP285660500), Robert Wood Johnson Foundation, CHEST Foundation, and the American Thoracic Society Foundation. Dr. Press is currently supported by the National Heart, Lung, And Blood Institute of the National Institutes of Health (Award Numbers R03HL144883 and R01HL146644) and the American Lung Association. Dr. Press also discloses consulting for Humana and Vizient and has consulted for RoundGlass within the past three years. Dr. Kan's effort was supported by grant number K12 HS026385-01 from the Agency for Healthcare Research and Quality (AHRQ). The content is solely the responsibility of the authors and does not necessarily represent the official views of AHRQ. The remaining authors have no funding or conflicts of interest to report.

\section{References}

1. Payares-Salamanca L, Contreras-Arrieta S, Florez-García V, BarriosSanjuanelo A, Stand-Niño I, Rodriguez-Martinez CE. Metered-dose inhalers versus nebulization for the delivery of albuterol for acute exacerbations of wheezing or asthma in children: a systematic review with meta-analysis. Pediatr Pulmonol. 2020;55(12):3268-3278. doi:10.1002/ppul.25077

2. Capanoglu M, Misirlioglu ED, Toyran M, Civelek E, Kocabas CN. Evaluation of inhaler technique, adherence to therapy and their effect on disease control among children with asthma using metered dose or dry powder inhalers. J Asthma. 2015;52(8):838-845. doi:10.3109/ 02770903.2015.1028075

3. Giraud V, Roche N. Misuse of corticosteroid metered-dose inhaler is associated with decreased asthma stability. Eur Respir J. 2002;19 (2):246-251. doi:10.1183/09031936.02.00218402

4. Melani AS, Bonavia M, Cilenti V, et al. Inhaler mishandling remains common in real life and is associated with reduced disease control. Respir Med. 2011;105(6):930-938. doi:10.1016/j.rmed.2011.01.005

5. Al-Jahdali H, Ahmed A, Al-Harbi A, et al. Improper inhaler technique is associated with poor asthma control and frequent emergency department visits. Allergy Asthma Clin Immunol. 2013;9(1):8. doi:10.1186/ 1710-1492-9-8

6. Basheti IA, Reddel HK, Armour CL, Bosnic-Anticevich SZ. Improved asthma outcomes with a simple inhaler technique intervention by community pharmacists. J Allergy Clin Immunol. 2007;119(6): 1537-1538. doi:10.1016/j.jaci.2007.02.037
7. Carpenter DM, Roberts CA, Sage AJ, George J, Horne R. A review of electronic devices to assess inhaler technique. Curr Allergy Asthma Rep. 2017;17(3):17. doi:10.1007/s11882-017-0684-3

8. Fink JB, Rubin BK. Problems with inhaler use: a call for improved clinician and patient education. Respir Care. 2005;50(10):1360-1374; discussion 1374-1375.

9. Gillette C, Rockich-Winston N, Kuhn JA, Flesher S, Shepherd M. Inhaler technique in children with asthma: a systematic review. Acad Pediatr. 2016;16(7):605-615. doi:10.1016/j.acap.2016.04.006

10. Kamps AWA, Brand PLP, Roorda RJ. Determinants of correct inhalation technique in children attending a hospital-based asthma clinic. Acta Paediatr. 2002;91(2):159-163. doi:10.1080/080352502317285144

11. Guidelines for the diagnosis and management of asthma (EPR-3) NHLBI, NIH; September 25, 2017. Available from: https://www. nhlbi.nih.gov/health-pro/guidelines/current/asthma-guidelines. Accessed September 25, 2017.

12. 2020 GINA main report. Global Initiative for Asthma. Available from: https://ginasthma.org/gina-reports/. Accessed May 6, 2020.

13. Lavorini F, Magnan A, Dubus JC, et al. Effect of incorrect use of dry powder inhalers on management of patients with asthma and COPD. Respir Med. 2008;102(4):593-604. doi:10.1016/j.rmed.2007.11.003

14. Sleath B, Ayala GX, Gillette C, et al. Provider demonstration and assessment of child device technique during pediatric asthma visits. Pediatrics. 2011;127(4):642-648. doi:10.1542/peds.2010-1206

15. Basheti IA, Bosnic-Anticevich SZ, Armour CL, Reddel HK. Checklists for powder inhaler technique: a review and recommendations. Respir Care. 2014;59(7):1140-1154. doi:10.4187/respcare.02342

16. Kocks JWH, Chrystyn H, van der Palen J, et al. Systematic review of association between critical errors in inhalation and health outcomes in asthma and COPD. Npj Prim Care Respir Med. 2018;28(1):1-6. doi:10.1038/s41533-018-0110-x

17. Volerman A, Balachandran U, Siros M, Akel M, Press VG. Mask use with spacers/valved holding chambers and metered dose inhalers among children with asthma. Ann Am Thorac Soc. 2020;18 (1):17-22. doi:10.1513/AnnalsATS.202005-522CME

18. Van Der Palen J, Eijsvogel MM, Kuipers BF, Schipper M, Vermue NA. Comparison of the Diskus ${ }^{\circledR}$ Inhaler and the Handihaler ${ }^{\circledR}$ regarding preference and ease of use. J Aerosol Med. 2007;20(1):38-44. doi:10.1089/jam.2006.0565

19. van der Palen J, Klein JJ, Kerkhoff AH, van Herwaarden CL. Evaluation of the effectiveness of four different inhalers in patients with chronic obstructive pulmonary disease. Thorax. 1995;50 (11):1183-1187. doi:10.1136/thx.50.11.1183

20. Lenney J, Innes JA, Crompton GK. Inappropriate inhaler use: assessment of use and patient preference of seven inhalation devices. Respir Med. 2000;94(5):496-500. doi:10.1053/rmed.1999.0767

21. Holley S, Morris R, Knibb R, et al. Barriers and facilitators to asthma self-management in adolescents: a systematic review of qualitative and quantitative studies. Pediatr Pulmonol. 2017;52(4):430-442. doi:10.1002/ppul.23556

22. van der Palen J, Klein JJ, van Herwaarden C, Zielhuis GA, Seydel ER. Multiple inhalers confuse asthma patients. Eur Respir J. 1999;14(5):1034-1037. doi:10.1183/09031936.99.14510349

23. Alotaibi S, Hassan WM, Alhashimi H. Concurrent use of metered dose inhalers without spacer and dry powder inhalers by asthmatic children adversely affect proper inhalation technique. Internet J Pediatr Neonatol. 2011;13(1). doi:10.5580/2546

24. Chan DS, Callahan CW, Hatch-Pigott VB, et al. Internet-based home monitoring and education of children with asthma is comparable to ideal office-based care: results of a 1-year Asthma In-Home Monitoring Trial. Pediatrics. 2007;119(3):569-578. doi:10.1542/peds.2006-1884

25. Hagmolen of Ten Have W, van de Berg NJ, Bindels PJ, van Aalderen WM. Assessment of inhalation technique in children in general practice: increased risk of incorrect performance with new device. J Asthma. 2008;45(1):67-71. doi:10.1080/02770900701815 834 
26. Press VG, Arora VM, Trela KC, et al. Effectiveness of interventions to teach metered-dose and diskus inhaler techniques. A Randomized Trial. Ann Am Thorac Soc. 2016;13(6):816-824. doi:10.1513/Annals ATS.201509-603OC

27. Volerman A, Toups MM, Hull A, Press VG. Does inhaler technique align with confidence among African-American children and their parents? Ann Allergy Asthma Immunol. 2019;123(1):100-101. doi:10.1016/j.anai.2019.04.012

28. Azzi E, Srour P, Armour C, Rand C, Bosnic-Anticevich S. Practice makes perfect: self-reported adherence a positive marker of inhaler technique maintenance. NPJ Prim Care Respir Med. 2017;27(1):29. doi:10.1038/s41533-017-0031-0

29. Amin AN, Ganapathy V, Roughley A, Small M. Confidence in correct inhaler technique and its association with treatment adherence and health status among US patients with chronic obstructive pulmonary disease. Patient Prefer Adherence. 2017;11:1205-1212. doi:10.2147/PPA.S140139

30. Takemura M, Kobayashi M, Kimura K, et al. Repeated instruction on inhalation technique improves adherence to the therapeutic regimen in asthma. J Asthma. 2010;47(2):202-208. doi:10.3109/027709009 03581692

31. Rodríguez-Martínez CE, Sossa-Briceño MP, Nino G. A systematic review of instruments aimed at evaluating metered-dose inhaler administration technique in children. $J$ Asthma. 2017;54(2):1 73-185. doi:10.1080/02770903.2016.1198373

32. Normansell R, Kew KM, Mathioudakis AG. Interventions to improve inhaler technique for people with asthma. Cochrane Database Syst Rev. 2017;3:CD012286. doi:10.1002/14651858.CD012286.pub2

33. Akinbami LJ, Santo L, Williams S, Rechtsteiner EA, Strashny A. Characteristics of asthma visits to physician offices in the United States: 2012-2015 National Ambulatory Medical Care Survey. Natl Health Stat Rep. 2019;128:1-20.

34. Gundewar A, David R, Frey SM, Fagnano M, Halterman JS. Underutilization of preventive asthma visits among urban children with persistent asthma. Clin Pediatr (Phila). 2017;56(14):1312-1318. doi:10.1177/0009922816685816

35. Rydman RJ, Sonenthal K, Tadimeti L, Butki N, McDermott MF. Evaluating the outcome of two teaching methods of breath actuated inhaler in an inner city asthma clinic. J Med Syst. 1999;23 (5):349-356. doi:10.1023/a:1020525116505

36. Press VG, Arora VM, Shah LM, et al. Misuse of respiratory inhalers in hospitalized patients with asthma or COPD. J Gen Intern Med. 2011;26(6):635-642. doi:10.1007/s11606-010-1624-2

37. Volerman A, Toups M, Hull A, et al. Assessing children's readiness to carry and use quick-relief inhalers. J Allergy Clin Immunol Pract. 2019;7(5):1673-1675.e2. doi:10.1016/j.jaip.2018.11.040

38. Instructional videos. National Jewish Health. Available from: https:// nationaljewish.org/conditions/medications/asthma-medications /devices/instructional-videos. Accessed March 3, 2021.

39. Asthma information. South Side Pediatric Asthma Center Chicago. Available from: https://www.southsidekidsasthma.org/asthmainformation/. Accessed March 3, 2021.

40. Carpenter DM, Lee C, Blalock SJ, et al. Using videos to teach children inhaler technique: a pilot randomized controlled trial. J Asthma. 2015;52(1):81-87. doi:10.3109/02770903.2014.944983

41. Ammari WG, Al-Hyari N, Obeidat N, Khater M, Sabouba A, Sanders M. Mastery of pMDI technique, asthma control and quality-of-life of children with asthma: a randomized controlled study comparing two inhaler technique training approaches. Pulm Pharmacol Ther. 2017;43:46-54. doi:10.1016/ j.pupt.2017.02.002

42. Toumas-Shehata M, Price D, Amin basheti I, Bosnic-Anticevich S. Exploring the role of quantitative feedback in inhaler technique education: a cluster-randomised, two-arm, parallel-group, repeated-measures study. NPJ Prim Care Respir Med. 2014;24:14071. doi:10.1038/ npjpcrm.2014.71
43. Olson CA, McSwain SD, Curfman AL, Chuo J. The current pediatric telehealth landscape. Pediatrics. 2018;141(3):e20172334. doi:10.154 2/peds.2017-2334

44. Badawy SM, Radovic A. Digital approaches to remote pediatric health care delivery during the COVID-19 pandemic: existing evidence and a call for further research. JMIR Pediatr Parent. 2020;3 (1):e20049. doi:10.2196/20049

45. Portnoy JM, Waller M, De Lurgio S, Dinakar C. Telemedicine is as effective as in-person visits for patients with asthma. Ann Allergy Asthma Immunol. 2016;117(3):241-245. doi:10.1016/j.anai.2016.07. 012

46. Qato DM, Zenk S, Wilder J, Harrington R, Gaskin D, Alexander GC. The availability of pharmacies in the United States: 2007-2015. PLoS One. 2017;12(8):e0183172. doi:10.1371/journal.pone.0183172

47. Abraham O, Brothers A, Alexander DS, Carpenter DM. Pediatric medication use experiences and patient counseling in community pharmacies: perspectives of children and parents. $J$ Am Pharm Assoc. 2017;57(1):38-46.e2. doi:10.1016/j.japh.2016.08.019

48. Carpenter DM, Abraham O, Alexander DS, Horowitz K. Counseling of children and adolescents in community pharmacies: results from a 14-day observational study. J Am Pharm Assoc. 2016;56(3):266-269. e1. doi:10.1016/j.japh.2016.03.001

49. Crespo-Gonzalez C, Fernandez-Llimos F, Rotta I, Correr CJ, Benrimoj SI, Garcia-Cardenas V. Characterization of pharmacists' interventions in asthma management: a systematic review. $J \mathrm{Am}$ Pharm Assoc. 2018;58(2):210-219. doi:10.1016/j.japh.2017.12.009

50. Bosnic-Anticevich SZ, Sinha H, So S, Reddel HK. Metered-dose inhaler technique: the effect of two educational interventions delivered in community pharmacy over time. J Asthma. 2010;47 (3):251-256. doi:10.3109/02770900903580843

51. Petite SE, Hess MW, Wachtel H. The role of the pharmacist in inhaler selection and education in chronic obstructive pulmonary disease. J Pharm Technol. 2020;875512252093764. doi:10.1177/875512252 0937649

52. Axtell S, Haines S, Fairclough J. Effectiveness of various methods of teaching proper inhaler technique. J Pharm Pract. 2017;30 (2):195-201. doi:10.1177/0897190016628961

53. Hämmerlein A, Müller U, Schulz M. [Involving pharmacists in the management of asthma patients]. Z Evid Fortbild Qual Gesundhwes. 2010;104(2):92-98. doi:10.1016/j.zefq.2009.07.007.German.

54. Nguyen T-S, Nguyen TLH, Van Pham TT, Hua S, Ngo QC, Li SC. Pharmacists' training to improve inhaler technique of patients with COPD in Vietnam. Int J Chron Obstruct Pulmon Dis. 2018; 13:1863-1872. doi:10.2147/COPD.S163826

55. Basheti IA, Armour CL, Bosnic-Anticevich SZ, Reddel HK. Evaluation of a novel educational strategy, including inhaler-based reminder labels, to improve asthma inhaler technique. Patient Educ Couns. 2008;72(1):26-33. doi:10.1016/j.pec.2008.01.014

56. Bynum A, Hopkins D, Thomas A, Copeland N, Irwin C. The effect of telepharmacy counseling on metered-dose inhaler technique among adolescents with asthma in rural Arkansas. Telemed $J$ E Health. 2001;7(3):207-217. doi:10.1089/153056201316970902

57. Locke ER, Thomas RM, Woo DM, et al. Using video telehealth to facilitate inhaler training in rural patients with obstructive lung disease. Telemed E-Health. 2019;25(3):230-236. doi:10.1089/tmj.20 17.0330

58. Coffman JM, Cabana MD, Yelin EH. Do school-based asthma education programs improve self-management and health outcomes? Pediatrics. 2009;124(2):729-742. doi:10.1542/peds.2008-2085

59. Geryk LL, Roberts CA, Carpenter DM. A systematic review of school-based interventions that include inhaler technique education. Respir Med. 2017;132:21-30. doi:10.1016/j.rmed.2017.09.001

60. Carpenter DM, Alexander DS, Elio A, DeWalt D, Lee C, Sleath BL. Using tailored videos to teach inhaler technique to children with asthma: results from a School Nurse-Led Pilot Study. J Pediatr Nurs. 2016;31(4):380-389. doi:10.1016/j.pedn.2016.02.005 
61. Perry TT, Turner JH. School-based telemedicine for asthma management. J Allergy Clin Immunol Pract. 2019;7(8):2524-2532. doi:10.1016/j.jaip.2019.08.009

62. Lin NY, Ramsey RR, Miller JL, et al. Telehealth delivery of adherence and medication management system improves outcomes in inner-city children with asthma. Pediatr Pulmonol. 2020;55 (4):858-865. doi:10.1002/ppul.24623

63. Crocker DD, Kinyota S, Dumitru GG, et al. Effectiveness of home-based, multi-trigger, multicomponent interventions with an environmental focus for reducing asthma morbidity: a community guide systematic review. Am J Prev Med. 2011;41(2 Suppl 1):S5S32. doi:10.1016/j.amepre.2011.05.012

64. Campbell JD, Brooks M, Hosokawa P, Robinson J, Song L, Krieger J. Community health worker home visits for medicaid-enrolled children with asthma: effects on asthma outcomes and costs. Am J Public Health. 2015;105(11):2366-2372. doi:10.21 05/AJPH.2015.302685

65. Marshall ET, Guo J, Flood E, Sandel MT, Sadof MD, Zotter JM. Home visits for children with asthma reduce medicaid costs. Prev Chronic Dis. 2020;17. doi:10.5888/pcd17.190288.

66. Pappalardo AA, Karavolos K, Martin MA. What really happens in the home: the Medication Environment of Urban, Minority Youth. J Allergy Clin Immunol Pract. 2017;5(3):764-770. doi:10.1016/j. jaip.2016.09.046

67. Martin MA, Rothschild SK, Lynch E, et al. Addressing asthma and obesity in children with community health workers: proof-of-concept intervention development. BMC Pediatr. 2016;16. doi:10.1186/ s12887-016-0745-0
68. Asthma care coverage initiative. Available from: https://www.lung. org/policy-advocacy/healthcare-lung-disease/asthma-policy/asthmacare-coverage. Accessed December 17, 2020.

69. Raiche T, Visentin JD, Fernandes L, Crown N, McCarthy LM. Quality improvement: a strategy to accelerate pharmacist integration into team-based primary care practice. Can Pharm J. 2020;153 (5):274-279. doi:10.1177/1715163520948915

70. Trump Administration Drives Telehealth Services in Medicaid and Medicare | CMS. Available from: https://www.cms.gov/newsroom/ press-releases/trump-administration-drives-telehealth-servicesmedicaid-and-medicare. Accessed December 17, 2020.

71. List of Telehealth Services | CMS. Available from: https://www.cms. gov/Medicare/Medicare-General-Information/Telehealth/TelehealthCodes. Accessed December 17, 2020.

72. TELEHEALTH MEDICAID and STATE POLICY $\mid$ CCHP Website. Available from: https://www.cchpca.org/telehealth-policy/telehealthmedicaid-and-state-policy. Accessed December 17, 2020.

73. Teaching patients to use an inhaler or nebulizer - Article Codapedia $^{\mathrm{TM}}$. Available from: https://www.codapedia.com/article 184_Teaching_patients_to_use_an_inhaler_or_nebulizer.cfm. Accessed December 17, 2020.

74. Self TH, Arnold LB, Czosnowski LM, Swanson JM, Swanson H. Inadequate skill of healthcare professionals in using asthma inhalation devices. J Asthma. 2007;44(8):593-598. doi:10.1080/02770900 701554334
Patient Preference and Adherence

\section{Publish your work in this journal}

Patient Preference and Adherence is an international, peer-reviewed, open access journal that focusing on the growing importance of patient preference and adherence throughout the therapeutic continuum. Patient satisfaction, acceptability, quality of life, compliance, persistence and their role in developing new therapeutic modalities and compounds to optimize clinical outcomes for existing disease

\section{Dovepress}

states are major areas of interest for the journal. This journal has been accepted for indexing on PubMed Central. The manuscript management system is completely online and includes a very quick and fair peer-review system, which is all easy to use. Visit http:// www.dovepress.com/testimonials.php to read real quotes from published authors. 